\section{BY THE NUMBERS}

\section{Belgíum}

\section{BY KATHARINE SANDERSON}

$\mathrm{F}$ amed for its beer, chocolate and the statue of a urinating boy in its capital, Belgium also has a well established scientific heritage. The country excels in biotechnology and space science, and has a world-leading nanotechnology research centre, the Interuniversity Microelectronics Centre in Leuven. Belgium also has the world's highest number of clinical trials per capita; this has been attributed to the nation's research capacity and very short time to approval for Phase I trials, compared with other European nations. The science budgets of Flemish-speaking Flanders and French-speaking Wallonia are administered separately, as is that of the small Brussels-Capital Region. Collaboration between individual researchers is not unusual, but there are few formal mechanisms to promote cross-region collaboration.

\section{GOVERNMENT BUDGETS ALLOCATED TO RESEARCH AND DEVELOPMENT}

Belgium's research funding has increased in general over the last 12 years, both regionally and country-wide.
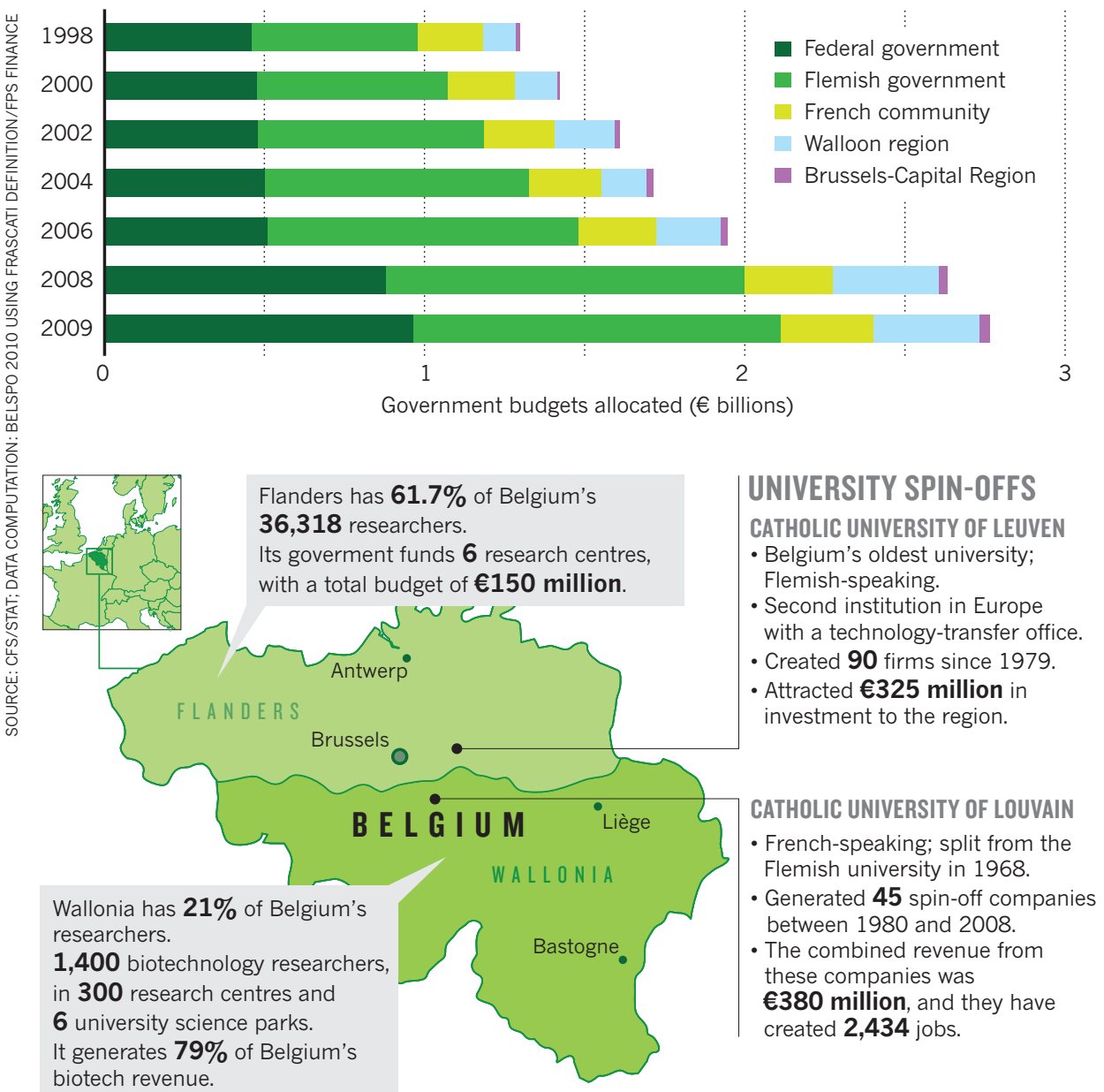

\section{EMPLOYMENT IN THE CAPITAL}

- The remaining $16.6 \%$ of researchers are in the Brussels-Capital Region.

- Brussels-based biopharmaceutical company UCB (Union Chimique Belge) is building a biotechnology plant at its Braine-l'Alleud site. The plant, which will produce drugs for clinical trials in nervous system and immunological diseases, is scheduled to open in 2012 and will employ 100 professionals.
08A Elisabeth Monard

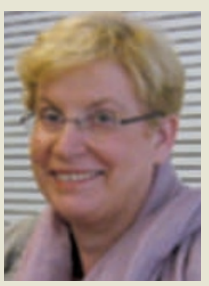

The secretary general of the Research Foundation Flanders (FWO) in Brussels, which is responsible for much of the region's science funding, discusses its scientific research prospects.

What is the FWO's budget? Since the mid-1990s, the Flemish government's budget for science has doubled. The FWO's budget for this year is almost $€ 195$ million (US\$268 million). For 2011 there could be a $5 \%$ cut, but we are optimistic, because the government has said that it has a plan for 2012 onwards, to invest more in science.

\section{Is Belgium a good place for young} scientists?

I think so. At the FWO we have fellowships for $\mathrm{PhD}$ students and postdocs. Only those with a master's from a European university can apply for the PhD fellowship. Our postdoc fellowships are open to all nationalities. We get more applications each year.

What opportunities exist in Belgium for foreign researchers?

We have a programme, Odysseus, to attract top senior and mid-career researchers. A university offers a position, and we offer funding, up to $€ 1.5$ million a year for five years. From 2011 onwards we will start a new programme, co-funded with the European Commission's Marie Curie Actions scheme, to attract more postdocs from other countries.

\section{How international are Belgian scientists?}

We have programmes to help our researchers move to other research groups all over the world. FWO fellows get a bench fee, which gives them mobility. And researchers can apply for grants to go abroad for up to a year. We are a bit afraid that our good researchers will go elsewhere because of the shrinking budget. I'm not worried that they are leaving, rather that they won't come back. K.S 